\begin{tabular}{|c|c|}
\hline & $\begin{array}{l}\text { Available online on } 15.07 .2018 \text { at http://jddtonline.info } \\
\text { Journal of Drug Delivery and Therapeutics } \\
\text { Open Access to Pharmaceutical and Medical Research }\end{array}$ \\
\hline JDDT & $\begin{array}{l}\text { (C) 2011-18, publisher and licensee JDDT, This is an Open Access article which permits unrestricted non- } \\
\text { commercial use, provided the original work is properly cited }\end{array}$ \\
\hline
\end{tabular}

Open

Access

Research Article

\title{
PREVALENCE OF POSTPARTUM DEPRESSION AND ITS ASSOCIATION WITH ANTENATAL DEPRESSION AMONGST WOMEN
}

\author{
Farhin Zaidi $^{1}$, Rubi Anjum ${ }^{1}$, Aruna Nigam ${ }^{2}$ \\ New Delhi-110062, India \\ ${ }^{2}$ D/o Obstetrics \& Gynecology, HMSR, Jamia Hamdard, New Delhi-110062, India
}

${ }^{1}$ D/o Tahaffuzi wa Samaji Tib (Preventive \& Social Medicine), School of Unani Medical Education \& Research, Jamia Hamdard,

\section{ABSTRACT}

Background: A prospective cross sectional study was designed to determine the prevalence rate of postpartum depression and its association with antenatal depression among women coming to the antenatal Clinic and birthing at HAHC Centenary Hospital, New Delhi.

Material \& Methods: 149 women by the assistance of EPDS (Hindi version) were screened at 6 weeks of their delivery. The participants were then divided on the basis of presence and absence of depression into two groups as depressed and non-depressed women.

Results: 19 out 149 postnatal women scored $\geq 10$ on EPDS which suggest the $12.75 \%$ prevalence rate of postnatal depression. Moreover 8(42.1\%) women among 19 depressed postnatal women and 25(19.3\%) women among 130 non-depressed postnatal women were found to have depression since their time of pregnancy thus a significant association $(\mathrm{p}$-value $=0.025)$ was obtained. Conclusion: PPD is a major health problem in our community. Moreover, presence of depression during pregnancy significantly predisposes the postnatal mothers to be a victim of PPD. Therefore an early screening of the perinatal women is needed to unreveal the hidden cases as well as to prevent the mothers from the cruel penalties of PPD.

Keywords: Postpartum Depression, Screening, perinatal women, Edinburgh Postnatal Depression Scale.

Article Info: Received 07 April, 2018; Review Completed 16 June 2018; Accepted 18 June 2018; Available online 15 July 2018

Cite this article as:

Zaidi F, Anjum R, Nigam A, Prevalence of postpartum depression and its association with antenatal depression amongst women, Journal of Drug Delivery and Therapeutics. 2018; 8(4):205-208 DOI: $\underline{\text { http://dx.doi.org/10.22270/iddt.v8i4.1766 }}$

*Address for Correspondence:

Dr. Rubi Anjum, Assistant Professor, D/o Tahaffuzi wa Samaji Tib (Preventive \& Social Medicine), School of Unani Medical Education \& Research, Jamia Hamdard, New Delhi-110062

\section{INTRODUCTION}

Postpartum depression (PPD) is an emerging concern of public health ${ }^{1}$ (Gulamini et al, 2013) PPD is the special state of mental health disorder and a variant of depression, commonly seen among general population of developed (10-15\%) and developing countries (11$42 \%)^{2,}{ }^{3}$ (Hegde et al, 2012 \& World Health Organization (WHO), 2011) PPD is a common non psychotic mood disorder that can begin in pregnancy, right after birth or anytime within the first year of delivery, generally observed within 4-6 or 6-8 weeks of delivery and possible as late as 30 weeks postpartum and the causative factor behind this malady is believed to be biological or psycho-social $4,5,6,7,8$ (Bodnar, Ryan \& Smith n.d, Hagen1999, Moraes 2006, Patel, Rodrigues \& Desouza 2002, Sadock \& Sadock, 2007) klainin \& Arthur, 2009 established the occurrence of PPD among Asian countries extended from 3.5\% to 63.3\% where Malaysia and Pakistan has the lowest and highest count respectively. Moreover one quarter of Asian women are supposed to be indulged by PPD as $23 \%, 28 \%$ and $22 \%$ occurrence rate of PPD was noticed in India, Pakistan and Bangladesh respectively, (Gausia et al, 2012) ${ }^{9}$. Chandra ${ }^{10} 2004$ in a study found $16-23 \%$ rate of prevalence of PPD among the two different states in India similarly, Doke ${ }^{11}, 2013$, Gupta ${ }^{12}$ et al, 2010 and $\mathrm{Hegde}^{2}$ et al, 2012, found an increase in epidemiological 
data on PPD in India, ranging from 11-33\%. Thus, the above figures are somewhere indicating that an immediate action is a requisite to control over the increments in the rate of prevalence of PPD worldwide.

According to the American Psychological Association the consent of PPD ranges from pregnancy to after childbirth moreover it was also suggested by the American Psychiatric Association that depression can affect women with easy or challenging pregnancy ${ }^{13,14}$. Depending upon the susceptibility, it executed both positive and negative influence on women's health ${ }^{15}$ (Mina et al 2012).Some women just sparkle, some have anxiety, while the patient whose personality shows neurotic traits may find it more difficult to adapt to her

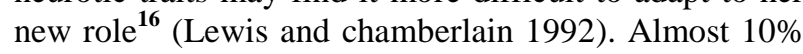
of pregnant women meat Diagnostic criteria for major depression $^{17}$ (Cunninghum, et al 1992). American Congress of Obstetrics and Gynecology (ACOG) 2009 recommended the 14-23\% occurrence rate of antenatal depression ${ }^{18}$. It has been shown by studies that minor illness in first trimester of pregnancy does not increase the risk of depression Postpartum, whereas, the women who have had such neurotic illness in last trimester are at increased risk of developing PPD ${ }^{\text {19-21 }}$ (Arulkumaran et al, 2012) Husain et al, 2006 and Ozmen et al, 2014, called psychopathy in antenatal period a key to predictor of PPD. Kieffer et al, 2013 found a strong correlation between antepartum and PPD ${ }^{\mathbf{2 2}}$. Stewart et al, 2003 considered 'depression during pregnancy ' as the strongest predictor of PPD. Furthermore, many other studies cited ante-partum depression as a high risk factor of PPD ${ }^{23}$. (Blom et al, 2012, Freeman \& Cohen, 2012, Klainin \& Arthur, 2009, Leigh \& Milgram, 2008, Robertson, et al, 2004, Rocaht et al, 2011, Sierra, 2008) Chandran et al, 2002 \& Patel, Rodrigues \& Desouza, 2002, found that $16 \%$ and $78 \%$ cases of PPD were having depression since their pregnancy respectively ${ }^{\mathbf{6}, 8}$ 24-30. Chandran et al, 2012, \& Patel Rodrigues \& Desouza, 2002) likewise Ocaktan et al, 2006, in a study found $31.8 \%$ rate of prevalence of depression during pregnancy 6, 30, 31. Great figures of women anguished with PPD had symptoms of antenatal depression with recommends the necessity of familiarizing antenatal screening for depression(LaMonde, n.d) Therefore, paper is intended to present the rate of occurrence and association of Postpartum depression (PPD) and its association with antenatal.

\section{MATERIAL AND METHODS}

\section{Study design:}

Present study is a Prospective cross-sectional study which was undertaken to ascertain the prevalence rate of PPD and its association with antenatal depression.

\section{Study Duration Setting and Participant:}

The present study was conducted from March 2014 to October 2014 in HAH Centenary Hospital, New Delhi. The setting is reputed Hospital located in an urban area of the state and provides antenatal, postnatal and immunization services for mother and their newborn. All antenatal women at $\geq 36$ weeks of pregnancy willing to deliver at the same setting were included in the study.
However, those who were the known case of chronic diseases like diabetes hypothyroidism etc. were excluded from the study.

\section{Method of Data Collection:}

An informed consent from each participant was obtained first. All antenatal women then interviewed at the respective setting by using the screening questionnaire. Moreover, the Diagnostic data and of statically details from each participant were also taken. Screening of each participant was repeated at 6 weeks of their delivery and those who were lost to meet at the end of their puerperium were excluded from the study.

\section{Sampling of the study:}

The sample size of study was 246 subjects calculated by assuming the $20 \%$ prevalence rate however by adopting the continuous sampling technique 263 antenatal women coming to the antenatal clinic of $\mathrm{HAH}$ Centenary Hospital New Delhi were screened at $\geq 36$ weeks of their pregnancy. Moreover, among all those 263 participants total 149 women were made to screen at 6 weeks of their child birth

\section{Tool for Screening of Depression:}

Screening of all participants was performed by using Edinburgh postnatal depression scale (EPDS). The scale is famed worldwide for its specific and sensitivity in the assessment of depression among the postnatal as well as the antenatal women. It comprises of 10 questions with scores ranged from zero to 3 does the total score varies as from zero to 30 . Moreover 7 out of 10 questions are scored reversely the tool has been validated in many languages $^{2}$ (Hedge et al, 2012). Moreover, Hindi translated version of the scale was used in the current study. A score $\geq 10$ was considered as existence of depression the reliability of questionnaire was also assessed whose Cochrane's Alpha value comes to lie within range of 0.814 to 0.844 which was quite reliable.

\section{Statistical Analysis:}

Data of the present study was analyzed by the using chisquare techniques moreover the reliability of the EPDS was also estimated. Whole process carried out by the help of SPSS version 17.

\section{RESULTS}

Total 263 antenatal women were approved for the assessment of depression; none of the antenatal women refuse to participate in the study but among those 263 participants 149 women were made to screen at 6 weeks of their child birth and the remaining 114 participants were excluded from the study. Assessment was carried out among those recruited 149 postnatal women by dividing them into two groups as depressed and is equal to 19 and non-depressed women and is equal to 130 .

Out of 231 postnatal women, majority belong to the age group of 26-29 years (47.0\%). A higher proportion of the participants were Hindus $(69.1 \%)$, living in joint families $(63.8 \%)$, graduate by their education $(38.3 \%)$ and unemployed $(75.2 \%)$ by occupation. Moreover, greater number of women was primipara $(74.5 \%)$ and had no history of previous abortion $(73.2 \%)$. 
Regarding the prevalence rate of depression during pregnancy it was observed that out of 263 antenatal women 33 women scored $\geq 10$ on EPDS at 36 weeks off pregnancy. Likewise, among 149 postnatal women 19 postnatal women scored $\geq 10$ on EPDS at 6 weeks of their delivery. Thus the rate of antenatal and postnatal depression comes out was $12.54 \%$ and $12.75 \%$ respectively. Moreover, the association between the two groups was also estimated (Table 1).

Table1: showing comparison between the depressive and non-depressive group on the basis of presence or absence of antenatal depression (at $\geq 36$ week).

\begin{tabular}{|c|c|c|c|c|c|c|c|}
\hline \multirow[t]{3}{*}{ Antenatal Depression } & \multicolumn{4}{|c|}{ Group } & \multirow{2}{*}{\multicolumn{2}{|c|}{ Total }} & \multirow[t]{2}{*}{ Chi-square value } \\
\hline & \multicolumn{2}{|c|}{$\begin{array}{l}\text { Depressed } \\
(\mathrm{N}=19)\end{array}$} & \multicolumn{2}{|c|}{$\begin{array}{l}\text { Non-Depressed } \\
(\mathrm{N}=130)\end{array}$} & & & \\
\hline & (n) & $(\%)$ & (n) & $(\%)$ & $(\mathrm{N}=149)$ & $(\%)$ & 5.031 \\
\hline Absent & 11 & 57.9 & 105 & 80.8 & 116 & 77.9 & $(\mathrm{p}$-value $=0.025)$ \\
\hline Present & 8 & 42.1 & 25 & 19.2 & 33 & 22.1 & \\
\hline
\end{tabular}

\section{DISCUSSION}

The estimated rate of prevalence of PPD (12.75\%) was found consistent to various other studies of community. For instance, Desai, Mehta and Jaishree, 2012 conducted a cross-sectional study in which 200 Gujarati postnatal women (above 18 years of age) within first postpartum year were interviewed ${ }^{32}$. The rate of prevalence of PPD they estimated was $12.5 \% \cdot{ }^{12} \mathrm{Gupta}$ et al, 2010 conducted a Cross-sectional study to evaluate the frequency of PPD among 202 women of Delhi and its neighboring states; $15.8 \%$ prevalence rate of PPD was estimated. Moreover, ${ }^{11}$ Doke 2013, in a study focused to established the maternal morbidities and estimates from community studies in India and found that the rate of prevalence of PPD in India as varied from $11 \%$ to $33 \%$. The outcome of the present study thus found equivalent with that of various other studies of developed as well as developing countries.

The high prevalence rate of antenatal depression $(12.54 \%)$ was too observed in the study. Moreover, It was also revealed that $42.1 \%$ of depressed women and $19.2 \%$ of non-depressed women were suffering from depression since there antenatal period (Table 1). Thus a very high rate of antenatal depression was observed among the subjects of PPD. Consequently, (pvalue $<0.05)$ (Table1). The occurrence of depression in pregnancy could be the resultant of numerous other significantly associated risk factors of PPD such as; low social support, poor marital relationship, unplanned pregnancy etc. (Beck 2002) ${ }^{33}$. Thus the finding of ours seems to be similar to the findings giving by Stewart et al, 2003, according to, which antenatal depression is one of the predictor of PPD. Equally, to the findings of the study conducted by Roomruangwong \& Epperson 2011, who reviewed the rate of prevalence and the associated risk factors of PPD among Asian countries, the subsequent rate of depression during antenatal and postnatal period they found was $20 \%$ and $21.8 \%$ respectively ${ }^{34}$. Similarly, the study carried out in Goa in 2002 by Patel, Rodrigues and Desouza reveal that $78 \%$ of total postnatal women suffering from PPD at 6-8 weeks and 6 months post-delivery were having depression, since their time of pregnancy another study was conducted in China by Siu et al, 2012 who determined the risk factors for PPD with special focus on the antenatal risk factors and introduced a significant relationship between PPD $^{31,35}$ and antenatal depression with relative risk of 3.90. Likewise, two studies carried out by Leigh and Milgrom, 2008 and Tsao, Creedy \& Gamble, 2014, explored the prevalence and psychological risk factors for PPD in new mothers living in Melbourne, Australia and Southern Taiwan respectively ${ }^{26,36,37}$. They also identified the antenatal depression as the strong predictor of PPD. Thus it could be derived from the previous and the present studies that depression during pregnancy raises the probabilities of development of PPD among women of diverse cultures.

\section{CONCLUSION}

PPD is a major health problem in our community. More over presence of depression during pregnancy significantly predisposes the postnatal mothers to be a victim of PPD. Therefore an early screening of the perinatal women is needed to; unrevealed the hidden cases as well as to prevent the mother from the cruel penalties of PPD.

Acknowledgement: Special thanks to all subjects of our study who generously devoted their valuable time to the study.

Funding: No funding was received for this research.

\section{Conflict of interest: No}

Ethical Approval: The present study was approved by the members of Board of Research Scholars and Ethical Committee of Jamia Hamdard on 16 August 2013 and 27th February 2014 respectively. 


\section{REFERENCES}

1. Gulamini S.S., Premji S.S., Kanji Z.K., Azam S.I. A review of Postpartum depression preterm birth and culture, The Journal of Perinatal and New Natal Nursing; 2013; 27(1):52-59.

2. Hedge S., Bhat K.S., Sharma M.S., Kamath P.S.V.N., Shetty A,K., Postpartum depression: Prevalence and Associated Factors Among women in India, Journal of women's health Issues and care; 2012; 1(1).

3. World Health Organization, Postpartum Depression: An Overview of Treatment and Prevention, 2011 [cited on $12^{\text {th }}$ December 2014] Available from: http:// www.gfmer.ch/SRHCourse-2011/ maternal health/ pdf/ Postpartum depressioncorey-2011.pdf.

4. Bodnar D, I., Ryan and Smith, J.E, n.d., Self-care program for women with Postpartum depression and anxiety [cited on, $2^{\text {nd }}$ August 2014]. Available from: http://www.bcapop.ca/ uploads/9/9/0/1/9901389/reproductive mental healthselfcareguide.pdf>

5. Moraes I,G,S., Pinheiro Dasilvaa R.T., Hortac R, A., Sousab P, L, R., Fariab A,D. Prevalence of Postpartum depression and associated factors. (pp.1-6) Rev Saude Publica; 2006; 40(1).

6. Patel V., Rodriues M., Desouza N. Gender, Poverty and Postnatal depression: A study of mothers in Goa India, American journal of psychiatry; 2002; 159:43-47.

7. Sadock B, J, Sadock V.A. (2007) kalpana's and sadock's concise textbook of clinical psychiatry, $3^{\text {rd }}$ Edition, (pp.406407) Wolters Kluwer, Lippincott Williams and Wilkins.

8. Klainin P, Author D.G. Postpartum Depression in Asian cultures: A literature review, International Journal of Nursing Studies, 2009; 46(10):1355-1373.

9. Gausia k., Ryda D., Ali M., Fisher C., Moran A Koblins M, ky. Obstetrical complications and psychological well-being: Experience of Bangladeshi women during pregnancy and childbirth, Journal of Health Population and Nutrition; 2012; 30(2):172-180

10. Chandra P.S. Postpartum Psychiatric care in India: The need for integration \& innovation, world Psychiatry, 2004; 3(2):99100.

11. Doke P.P, Maternal morbidities and estimates from community studies in India, MGM Journal of Medical Sciences; 2013; 1(1):57-65.

12. Gupta S. Jugal K., Mala Y. M., Ramji S. Agarwal R. Postpartum depression in North India women: Prevalence and risk factors. The journal of obstetrics and Gynecology of India; 2010; 63(4):223-229

13. American psychological Association, Postpartum depression [Cited on 21 ${ }^{\text {st }}$ July2014] Available from: http://www.apa.org/pi/women/resources/reports/postpartumdepr.aspx

14. American Psychiatric Association, Postpartum Depression [Cited on $11^{\text {th }}$ May 2014]. Available fromhttp://www.psychiatry.org/Postpartum depression

15. Mina S., Balhara Y, P, S., Verma R., Mathur A. Anxiety \& Depression amongst the urban females of Delhi in Antepartum and Postpartum Period, Delhi Journal of Psychiatry; 2012; 15(2):347-351.

16. Lewis T.L.T., Chamberlain G,V,P. (1992). Obstetrics by 10 teachers $15^{\text {th }}$ Edition, (122-128) English Language Book Society.

17. Cunninghum F.G., McDonald P.C., Gant N.F., Levono K.J., Gilstrap L.C., Hankins G.D.V and Clark, SL,(1997) Williams Obstetrics, $20^{\text {th }}$ Edition, (pp.1265-1268) Prentice-Hall International, INC.

18. American Congress of Obstetrics and Gynaecology (ACOG), Depression During Pregnancy: Treatment Recommendations, 2009 [Cited on $14^{\text {th }}$ December 2014].

19. Arul Kumaran S., Sivanesaratnam V., Chatterjee V, Kumar P., (2011) Essentials of Obstetric $2^{\text {nd }}$ Edition (pp. 510-511) Jaypee Brothers Medical Publishers (P) LTD.

20. Husain N., Bevem Im, Husain M., Chaudhary I,B., Atif N., ,Rahman A. Prevalence and Social correlates of Postnatal depression in a low income country, Archives of women's Mental Health, 2006; 9(4):197-202

21. Ozmen D., Cakmak A., Cetinkaya Ulas S,C., Ozmen, E., Association between perceived social support and Postpartum depression in Turkey, British Journal of Medicine and Medical Research; 2014; 4(10):2025-2036.

22. Kieffer,E, C., Caldwell C,H., Welmarink D, B., Welch K.B., Sinco B, R., Guzman'n J,R., 2013, Effect of the Healthy MOMs Lifestyle intervention on reducing Depressive symptoms Among Pregnant Latinas, American Journal of Community Psychology, Available from <http//:www. ncbi.nlm.nih.gov/pubmed/ 22638902>

23. Stewart D,E., Robertson E., Dennis C,L., Grace S,L., Wallington T. Postpartum Depression: Literature Review of Risk factors And Interventions, Tomato Public Health, 2003, pp. 2 Available from: http:// www.w ho. Int/ mental_ health/prevention/suicide/lit__ review-postpartum _depression.pdf [21 ${ }^{\text {st }}$ October 2014]

24. Blom E,A., Jansen P.W.,Verhust F.C., Hofman, A., Raat H., Jaddoe VWV,. Coolman M, et al, Perinatal complications increase the risk of Postpartum depression, British Journal of Obstetrics and Gynaecology (BJOG); 2010; 117:1390-1392.

25. Freeman M.P., Cohen L.S. Postpartum depression: Help patients find the right treatment, Current psychiatry; 2012; 11(11):14-21.

26. Leigh B., Milgrom J., Risk factors for antenatal depression, Postnatal depression and parenting stress, BMC psychiatry 2008; 8(24):121-127.

27. Robertson E., Grace S., Wallington T Stewart D.E. Antenatal Risk factors for Postpartum depression: A synthesis of recent literature, General Hospital psychiatry; 2004; 26(4):289 -295.

28. Rocaht T,J., Tomlinson M., Barnighausen T., Newell M, L., Stein, A. The prevalence and clinical presentation of antenatal depression in rural South Africa, Journal of Affective Disorders; 2011; 13(5):362- 373.

29. Sierra J. (2008). Rrisk factors related to postpartum depression in low- income Letina mothers. Doctoral dissertation, University of Connecticut. Available from :http:// digital commons, uconn.edu/ dissertations/AA 1327 9301/

30. Chandran M., Tharyan P., Moliyil J., Abraham S., Postpartum depression in a Cohort of women from a rural area of Tamil Nadu India: Incidence and risk factors, British Journal of psychiatry; 2002; 181:499-504.

31. Ocaktan M.E.,CalisKan D., On cu, B., Ozdemeir O., Kose K. Antepartum and Postpartum depression in a Primary Health Care Centre area, Journal of Ankara University Faculty of medicine, 2006; 59(4):151-157.

32. Desai N., Mehta R.Y., Ganji wala J. Study of Prevalence and risk Factors of Postpartum depression, National Journal of Medical Research; 2012; 2(2):194-198.

33. Beck C,T, Rrevision of the Postpartum depression predictors inventory Journal of Obstetrics Gynaecology and Neonatal Nnursing; 2002; 31(4):394-402.

34. Roomruangwong $\mathrm{C}$ Epperson C,N. Perinatal depression in Asian women: Prevalence associated factors and cultural aspects, Asian biomedicine 2011; 5(2):179 -193

35. Siu BWM., Leung SSL., Patrick IP., Hung SF. OHara, M. Antenatal risk factors for postnatal depression: A Prospective study of Chinese women at maternal and Child Health centers, BMC Psychiatry; 2012; 12(22).

36. La Monde A., (n.d) Comprehensive review of Postpartum depression for healthcare providers [CIted on $18^{\text {th }}$ May 2014] Available from <http//:www mostonline.org/PPD_comprehensive review.pd.

37. Tsao Y, Creedy D.K, Gamble J, (2014) Prevalence and psychological correlates of postnatal depression in rural Taiwanese women, Health care for women International [viewed on $12^{\text {th }}$ February 2015] .Available from http:// www.tandfonline.com/doi/abs/ 332.2014.946510\#. VM 98Fv6Ud3Q. 